\title{
Leadership Models and Leadership Styles as Success Factors in Small and Medium-sized Enterprises
}

\author{
http://doi.org/10.21272/bel.4(1).35-42.2020
}

Georg Thomas, ORCID: https://orcid.org/0000-0002-6866-2970

$\mathrm{PhD}$ Candidate, Head of Research \& Development, Faculty of Economic Sciences, Kaposvár University, Kaposvár, Hungary

\begin{abstract}
Under conditions of the population aging, one of the most pressing and urgent problems for company management is the retirement of most administrative staff over the next few years. At the same time, the majority of the young working-age population brings into question the current management practices in companies, considering the work primarily as a way of ensuring their livelihoods. There is a large proportion of the population who believe that work should bring joy, pleasure, and be open to creative activity. It leads to a shift in small and medium-sized companies (SME) from traditional management models to those adapted to modern labor market requirements. It is considered that the advertising brochures and websites of many small and medium-sized enterprises have recently mentioned a standard management style when announcing a vacancy notice. As for the employees, the presence of joint management is considered as "the most important property of the company", while most managers treat the formation of this management style with a high degree of formality and conventionality. This article investigates the problems of trade companies in the context of the creation and implementation of labor-management policies. These challenges are widely described and discussed in the world of scientific literature, predominantly by the example of other industries, leading to inconsistencies in the conditions and features of its application in the trade sector. According to an empirical approach based on expert interviews, major leadership issues were identified. Experts stressed the fact that while struggling for skilled personnel, the companies face new challenges when the younger generation of employees emerges in the labor market. These workers require a more transformational approach to leadership than that one, which exists today. The reasons for this situation are the promotion of highly qualified specialists to executive positions. Thus, these vacancies are often replaced by those who earned it the most, being an excellent employee, but lack managerial skills.
\end{abstract}

Keywords: demographic trend, leadership styles, RIASEC model, small and medium-sized enterprises, transformational leadership, general management.

JEL Classification: J11, J19, M12, O15.

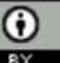

This work is licensed under a Creative Commons Attribution 4.0 International License

Cite as: Thomas, G. (2020). Leadership Models and Leadership Styles as Success Factors in Small and Medium-sized Enterprises. Business Ethics and Leadership, 4(1), 35-42. http://doi.org/10.21272/bel.4(1).3542.2020 .

(C) The Author, 2020. This article is published with open access at Sumy State University.

\section{Introduction}

Craft and trade enterprises are facing challenges that are barely addressed by management and leadership literature. Not unlike their non-crafts counterparts they face the challenges of digital transformation and its consequences on society (Bonfour, 2016) as well as demographic change (Bieling, Stock \& Dorozalla, 2015). The war for talent (Ulrich, 2015) as it was coined mostly for the field of IT seems just as relevant for crafts, as Hogeforster (2001) points out: There is a considerable lack of skilled employees in German trade and craft, a development that is growing stronger in recent years.

The field of trade and craft, Hogeforster (2001) further explains, is shaped by globalization and its consequences as well. While still typically having a more local focus, slowly companies in this field are also attracting international customers and are starting to embrace international partnerships. Thus, leadership in the field also has to open up to these new ideas and set new foci. Leadership approaches that are focused on collaboration both internally and externally, the expert argues, will therefore be of even higher importance in 
the future. Also, leadership has to put a high focus on quality, Hogeforster (2001) points out - especially in the field of trade and crafts in Germany. As Germany is known for highest quality in their products, high skilled employees are urgently needed in order to stay competitive on the international market. Finding and retaining such staff is therefore imperative for leaders and executives in this field.

The current paper will focus on these aspects, as it aims on answering the leading research question: In which ways can leadership contribute to helping the field of crafts and trade to successfully compete in the war for talent?

\section{Literature Review}

Among the reactions to the mega-trends of globalization and digitalization (Marin \& Verdier, 2012) are often discussed developments on the company side like transformational leadership (Bass, 1997) or sustainable HR management. Both these approaches try to introduce more modern and thus more adequate leadership and management in companies. This is not only a reaction to the general search for highly skilled workers but also to their raising and changing requirements and demands. Authors such as Klaffke (2014) point out that for the new generation of employees, the pay alone is not enough to be a motivational factor anymore. Rather, Klaffke (2014) identified a number of value clusters that influence young employee's wellbeing and motivation in the work setting: "Affiliation and Authenticity", "Transparency and Networking", "Performance", "Meaningfulness", "Development" and "Enjoyment" (Klaffke, 2014: 64).

Transparency is also demanded by Generation $\mathrm{Z}$ members in other areas of professional life: Together with the use of various networking tools, the need for clarity about goals and circumstances is also strongly emphasized. At the same time, authors such as Rohwetter (2013) state that the focus is no longer so much on ownership (of equipment or software, for example), but rather on the usability of the equipment at any time, which also explains the collaborative consumption of media in this generation.

The areas of enjoyment and performance are described as equally important, which corresponds to a departure from the fixation on the performance of earlier generations. This strong shift towards hedonism of the generation does not mean, however, that performance or success is significantly less important to them than previous generations, but rather that enjoyment and pleasure have also become more important. However, performance is sometimes experienced and described differently by Generation $\mathrm{Z}$ than by previous generations: For example, slow, unnoticed work, which would lead to long-term success, is no longer experienced as desirable; instead, preference is given to models that offer very rapid feedback - also gladly in the form of appropriate performance-related pay - on one's own performance (Klaffke and Becker, 2012). One can speak here, among other things, of the gamification of professional life (Thoma, 2011), an effect that has also found its way into other areas of life. Immediate feedback (whether in the form of Likes on Facebook or in the form of rewards in various games or apps such as Runtastic) is now a central component of youth culture. The same is expected of young people in the area of their work reality, where an annual appraisal interview as performance feedback no longer seems sufficient to them.

In order to motivate and attract young employees, companies have to react to these changing developments and adapt not only their leadership but also their HR management.

Examples of how modern management reacts to these requirements are given by Bhattacharya, Sen, and Korschun (2008). On the example of modern IT companies, the authors explain the usage of transformational management methods that try to combine the vision and goals of the company with the requirements given by the employees. Socially responsible behavior of the company is described as an important asset in the war for talent - it makes the company more attractive to highly skilled employees, thus playing into the company's employer branding and also minimizes turnover. Summarizing, authors such as Noe, Hollenbeck, Gerhart, and Wright (2017) describe that companies who make use of such approaches in their HR management gain a strategic advantage over other companies and will in the long-term be the succeeding ones.

At the same time, these management approaches - while apparently useful in all fields (Ferris, Russ, Albanese \& Marlocchio, 1990) - seem not to be implemented everywhere with the same success. Brandenburg, Haas, and Byrom (2006) argue that the construction industry, not unlike many industries in the field of crafts - is not "as diligent in implementing strategic HRM programs as other industries" (p. 89). In general, the authors complain that in this industry barely any formal HRM programs or leadership approaches exist, workforce planning and identification of key talents are not yet fully considered to be important tasks of managers and leaders in this field. The results of their empirical evaluation, however, 
proves that modern HRM approaches would be beneficial also in this field in which big parts of the workforce are less formally educated but still highly-skilled: "The construction industry has experienced a shortage of skilled craft workers and will continue to experience the shortage unless revolutionary methods are put in place to address the problem" (Brandenburg, Haas \& Byrom, 2006: 94).

In a similar vein, Behrens (2001) describes the problematic situation of crafts in Germany - while young employees are hard to motivate for employment in this field, the aging society provides a new challenge for companies in this field. Unlike typical office jobs, with growing age many tasks become harder or even impossible for employees, thus effectively limiting the staff availability even further - not only seems there to be a lack of young employees but also the older ones cannot fully perform for as long as in other fields. This, Behrens (2001) argues it is not only due to the physical limitations of the employees but also a result of discouraging management - older employees in crafts are often viewed as more fragile than they feel themselves, thus further contributing to the problem.

\section{Research Gap and Research Question}

The selection of these results opens up the research gap of this paper. While the bulk of management literature agrees that management or leadership style strongly impacts employee's motivation and well-being and thus, subsequently company performance, much less is known about the challenges that hinder sustainable and transformational leadership in small and medium enterprises in the field of crafts. These companies, however, seem to be in dire need of workforce and talents as well as other fields, while lacking partially the resources to attract and manage them.

The leading research question of this work, thus, is: With which leadership styles can managers in this field react to the changing and growing challenges?

\section{Material and Methods}

An empirical study based on expert interviews was conducted to answer this research question. The survey took the form of a guided interview. This format was chosen in compliance with the proposal of Sekaran and Bougie (2016), who argue that for open research questions of an explorative nature, methods that allow indepth exploration such as interviews are considered to be valuable tools. The method of a guided interview was chosen over more unstandardized forms as it still allows for in-depth answers while improving validity and reliability and thus, making the answers easier comparable and interpretable.

The interview contained question blocks both in regards to leadership challenges in the branch and to developments on the employees' side. Participants were asked to present their professional views on these topics.

Qualitative analysis of the interviews was conducted following the method proposed by Mayring (1988). The goal of this analysis was to identify which core challenges experts see for the field and to understand how well prepared for those the field seems to be.

In order to obtain many different points of view and thus be able to answer the research question comprehensively, the $n=6$ experts of this study were recruited from six different groups: business executives (interview partner 1/IP1), heads of consultancies (IP2), university (IP3) and continuing education institutions (IP4), and heads of the Chamber of Commerce (IP5) and Industry (IP6).

In order to increase the participation of the study participants, each prospective participant was personally asked in advance of the study if they would be willing to participate in the study. The concept of a personal address in advance was very successful, all the experts mentioned agreed. However, the experts were guaranteed anonymity, which allowed them to address problems and challenges in the field more easily.

Furthermore, each respondent received an e-mail with the interview questions on "Leadership Styles and Methods of Human Resource Management in SMEs" in advance. This ensured that all experts had a common understanding of leadership and, above all, of the aspects of interest in this work.

\section{Results of the Qualitative Study}

All of the six interviewees confirmed a change - possibly a paradigm shift - in the way leadership will be handled in the field of crafts in the upcoming years. They agreed that societal changes - especially in the 
upcoming generations (IP1, IP3) - would lead to a stronger need for the more appropriate management and leadership approaches.

All experts agreed that one of the core problems a majority of leaders in the field are facing at the moment is a lack of depth in their leadership with deficits in terms of social interactions and communications. IP1 summarized, that the typical approach to becoming a leader in the field of crafts is to be an outstanding engineer or craftsman, which leads to promotion. Key qualifications a leader might need (such as empathy, character strength and an understanding of the role itself) are typically not considered with such promotions (IP1, IP2, IP3, IP5, IP6). However, leadership positions - all six experts agreed - would need a clear understanding of leadership and the personal capabilities to turn this understanding into appropriate actions. This, IP3, IP4, and IP5 stated should be addressed both inside of the companies when making decisions about who should be promoted to leadership positions but also on a societal level, which would include better training and education of (potential) leaders in the fields of crafts. As IP3 stated, only around one percent of overall training time for practitioners is devoted to leadership aspects. This, IP3 further argues, contributes to the situation, all experts see as critical: Leadership positions in the field of crafts are typically field with persons (typically men, as IP6 stated) who excelled in their field of labour but are not necessarily skilled or prepared for leadership activities, that would require a stronger focus on people management than on labour skills.

Another challenge named by the experts is what IP1 described as the management sandwich. This stressful situation (which was under different labels or without such also mentioned by IP2, IP3, and IP4) describes the pressure on middle managers and leaders in this field from two sides. On the one hand, top management (often the owner of the company, as IP1 explains) wants to see measurable results and success, while those who are being managed would need further guidance. Thus, IP3 explains, it can become even for those leaders in the field who are willing and probably capable to actually lead, nearly impossible to actually do so. This problematic situation is further accentuated by the fact, that leaders are typically also involved still in the job itself - only very rarely can leaders in craft take on the role of leadership alone (IP5, IP6). Rather they typically still work on the job itself, while at the same time taking on leadership activities, which intensified the pressure (IP1).

Companies in which this situation is especially evident, IP1, IP2, and IP5 stated, are typically characterized by having a short-term focus on revenue and earnings. This, however, they further argue does not necessarily stem from overly greedy managers or owners but from a very high pressure in a market, that all six experts describe as extremely volatile and competitive. Thus, IP6 clearly states, the focus on leadership would be an important goal for companies to focus on, but at the same time one, for which most of them clearly lack the resources. Typical companies in the field thus experience a variety of struggles, IP2 states: they experience high-performance pressure, low identification of the employees with the company and low promotion chances for the employees. Here, in most cases leadership happens in a one-dimensional, that is transactional way, whereas transformational aspects are not considered (IP1, IP2, IP5). Especially the interviewees from the training and education (IP3 \& IP4) stated to be under excessive "collective overheating". Aggression, emotional exhaustion and a reduction in performance are often the result, IP1 summarizes the problem from his point of view.

Furthermore, all experts pointed out that the generational shift (as initially described by Klaffke, 2014) - is very visible to them. Approaches that were effective in the leadership of baby boomers seem to work less or not at all for the younger generation (IP3). While most leaders and managers of KMUs in the craft and trade field stem from the baby boomer generation still, young employees - so the experts (IP3, IP4, IP5) - have a hard time connecting to them. Rather members of these younger generations value participation in leadership situations and insist on their own values - much more than the generations before them, all experts conclude based on their own experiences with younger employees. Thus, one of the core challenges of SMEs in this field lays in leadership communication and leadership styles, IP3 states directly. Leaders are a) usually not chosen based on their leadership qualities but on seniority and craft skills and are b) on average far older than big parts of the staff (IP1, IP2, IP3, IP5, IP6). Both of these aspects lead to a growing challenge for companies in these fields, the experts point out. Especially the age gap between many employees (who tend to be young) and the leaders is pointed out to be a practical problem, IP1 explains. He describes that in many typical companies, there is a clear distinction between workers and leaders that can very directly be related to their respective age: While most of the workers are in their 20s, IP1 explains, most of the leaders are in their 
50s or even 60s. This gap - that in less detail is also explained by IP2, IP3, IP4, and IP5 - influences conflicts between the groups, who seem to lack mutual understanding for each other. Conflicts arise from this specific situation that can, in turn, lead to lower motivation (thus impacting performance negatively) and to higher turnover rates due to dissatisfaction with the management (IP1, IP5).

Another core challenge lays in the structure of trade and craft SMEs in general: Leaders are usually not only active in their position as leaders but are also actively working on other projects and are often involved in a multitude of different assignments and tasks (IP5, IP6). This was described by many of the experts as the leadership sandwich (IP1): Leaders often lack the time, energy and resources to actively focus on their leadership. Rather they are forced to fulfill other roles at the same time, often even with conflicting goals. While - so the experts agreed - many of the leaders in this field would be happy to focus more strongly on leadership and people development they simply lack the resources to do so. Especially in companies that deal with tight deadlines and short-sighted development goals - partially due to the competitive market situation that puts a stronger pressure on fast and cheap fulfillment of projects - leaders can only devote a small fraction of their time and resources on actual leadership. Rather they are forced into an urgency-importance tradeoff (IP5, IP6) see Lowy \& Hood, 2011). While an important long-term goal such as new leadership approaches and a stronger focus on the values and goals of the employees are considered, the time pressure forces leaders into focusing on urgent matters instead.

\section{Discussion}

The initial research question of this paper is: With which leadership styles can managers in this field react to the changing and growing challenges? The findings from the empirical study show, that in order to focus on the choice of leadership styles, a variety of initial hurdles have to be overcome. The generational gap between leaders and workers is one of those, along with a lack of leadership qualities, capabilities and personalities often found in this field. While throughout the interviews, proposals for more transformational leadership approaches were found, it still becomes clear from the findings, that in order to focus on the implementation of transformational leadership, a more conscious approach to leadership has to be taken first.

The results found in this empirical, exploratory study go in strong alignment with many findings from the literature. Especially what the experts agreed on about the values and goals of the younger generation of (potential) employees, goes along with the findings from Klaffke (2014). Payment alone is not enough as a motivator for young employees, rather they want to be heard and considered. Transformational leadership as initially proposed by Bass (1997) - was one of the earliest developments to take this into consideration long before the so-called generation $\mathrm{Y}$ or $\mathrm{Z}$ were pushing into the employment market. Transformational leadership can be considered to be a reaction to these developments, as it - unlike transactional leadership is not only based on a reward system that values good performance by offering (monetary) rewards but on an on-going and positive relationship between leaders and employees. A core challenge of transformational leadership, thus, is communication and the building of a positive relationship between them and their employees. While this approach is shown to be a successful one (Dumdum, Lowe \& Avolio, 2013) it also puts a strong emphasis on the leaders' personalities: Transformational leaders should be characterized by charisma (Jiang, 2018), integrity (Simons, 1999) and experience (Echevarria, Patterson \& Krouse, 2017). These characterizations, coincidentally, are the factors that many real-world leaders in small enterprises in the fields of craft and trade are lacking, the experts of the empirical study pointed out. As they are often not chosen based on their leadership or communication skills but rather on their qualities and skills in their actual field, this can be problematic. This also goes in alignment with the challenge of small and/or young companies that is described by the work of Rauch and Frese (2007). The authors point out that designated roles are often not yet a possibility for companies smaller than a certain threshold. Thus, single persons often have to take on multiple roles at the same time, which can lead to both conflicts and faster burn-out due to overwhelming requirements.

In this vein also the work on vocational interests has to be noted (Holland, 1997). The impactful RIASEC model proposed by Holland describes six categories of vocational interests - realistic, investigative, artistic, social, enterprising and conventional. People in the field of crafts are typically characterized by a strong realistic vocational interest, which described an interest in working with one's hands, with different materials and technological solutions. People with this dominating interest type are typically less interested in 
entrepreneurial or enterprising activities such as management or leadership, as the graphical representation of the model (see Figure 1) makes clear.

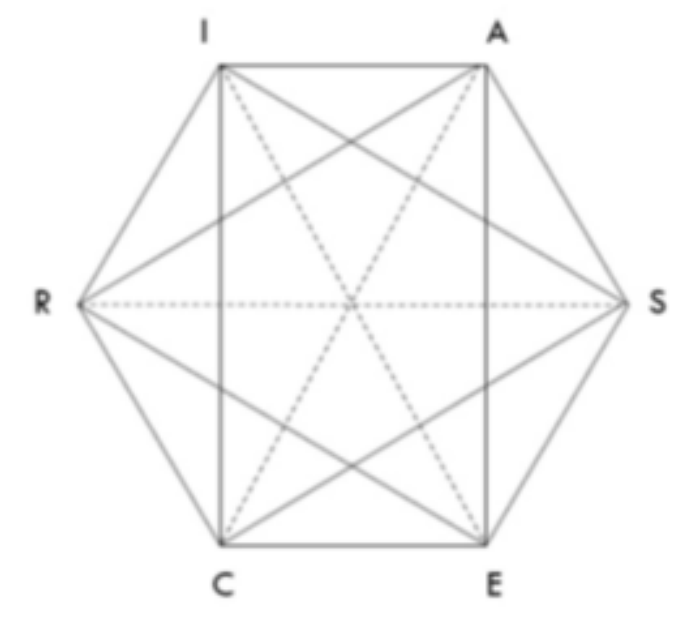

Figure 1. RIASEC model of vocational interests

Source: Tarnai \& Hartmann (2015: 16)

The closer two interest types are on the hexagonal model, the more related they are and the more likely they are according to Tarnai and Hartmann (2015) to be strongly developed in the same person. This implies that those strong in the field of crafts and trade might not even be very interested in leadership and management activities.

According to a meta-analysis of Van Iddekinge, Roth, Putka and Lanivich (2011) or the more recent work of Neubauer (2018) vocational interests or rather the match between one's vocational interest and the requirements of the job, predict performance outcomes. Concludingly Neubauer (2018) states, the more interested someone is, in what he does, the more successful he on average should be in this. This is a possible explanation for the results found throughout this work: Leaders in the field of craft and trade might be less interested in developing leadership approaches and would rather focus on the technical side of their work. This goes in alignment with the proposal of Hogeforster (2001) that horizontal career pathways in trades should exist - not every career change needs to be a promotion towards a managerial position, but rather different career steps in the trade positions itself should exist to allow for perspectives. This should - as the expert interviews showed - allow for motivation while avoiding pushing good workers into leadership positions they might neither want nor succeed in.

\section{Conclusions}

Concludingly this work was able to show that the craft and trade sector faces a multitude of challenges that other branches are facing as well - although often neglected by scientific research. The challenges even seem accentuated in this field, as the empirical analyses show: While the war for talent and the consequences of digital transformation and changing values in the younger generation impact SMEs in this field as much as in others, this field at the same time is often characterized by a lack of resources that can be devoted to management and leadership. Thus, leadership, people development, and similar long-term goals are often only handled as side-notes instead of as a priority, which is most strongly explained by a focus on urgent matters instead of important ones. At the same time, leadership positions are often filled as a result of promotions of good and skilled workers, who might lack the leadership qualities and education. This problem only grows with the influx of employees of the younger generation who demand a more transformational leadership approach.

Classical leadership approaches that were considered to be adequate for the previous generation thus seem to fall out of favour with the younger generation. At the same time, it seems to stay unclear how to develop leadership in the field of crafts, as one of the core problems within this field is the approach to leadership itself. Leaders in this field are often not chosen based on their leadership qualities or even aspirations but rather on their skills and qualifications in the crafts itself. Therefore, they often seem to lack both the interest and the know-how in order to fully commit to the leadership position, which would be an urgent requirement for leading this field to a more transformational direction in terms of leadership.

One of the core suggestions for practitioners in the field derived from the empirical study of the current paper therefore is, to focus on filling leadership positions in this field in a similar way as it is done in other 
fields and to put stronger focus on leadership training. As one of the experts interviewed for the study states, at the moment only a very small portion of training time is spent on leadership and managerial tasks. This might be one of the changes that need to be implemented in order to achieve higher leadership success and therefore actively work on succeeding in the war for talent.

\section{References}

1. Bass, B. M. (1997). Does the transactional-transformational leadership paradigm transcend organizational and national boundaries? American psychologist, 52(2), 130. https://doi.org/10.1037/0003066X.52.2.130.

2. Behrens, J. (2001). Handwerkstätigkeiten in kleinen Betrieben: bestandener Härtetest für betriebliche und individuelle Laufbahngestaltung [Craft activities in small businesses: passed endurance test for company and individual career development]. In Handwerkskammer Hamburg (Ed.). Zukunftsfähige Konzepte für das Handwerk zur Bewältigung des demographischen Wandels [Sustainable concepts for the craft trade sector to cope with demographic change]. Stuttgart: Frauenhofer IRB Verlag. https://www.ssoar.info/ssoar/bitstream/handle/document/23655/ssoar-2001-

zukunftsfahige_konzepte_fur_das_handwerk.pdf?sequence=1\&isAllowed=y\&lnkname=ssoar-2001zukunftsfahige_konzepte_fur_das_handwerk.pdf.

3. Bhattacharya, C. B., Sen, S., \& Korschun, D. (2008). Using corporate social responsibility to win the war for talent. MIT Sloan management review, 49(2), 37-44.

https://www.researchgate.net/publication/279905171_Using_Corporate_Social_Responsibility_to_Win_the_ War_for_Talent.

4. Bieling, G., Stock, R. M., \& Dorozalla, F. (2015). Coping with demographic change in job markets: How age diversity management contributes to organisational performance. German Journal of Human Resource Management, 29(1), 5-30. https://doi.org/10.1177/239700221502900101.

5. Bounfour, A. (2016). Digital futures, digital transformation. Springer International Publishing, Cham, Switzerland, 10, 978-3. https://doi.org/10.1007/978-3-319-23279-9.

6. Brandenburg, S. G., Haas, C. T., \& Byrom, K. (2006). Strategic management of human resources in construction. Journal of Management in Engineering, 22(2), 89-96. https://doi.org/10.1061/(ASCE)0742597X(2006)22:2(89).

7. Dumdum, U. R., Lowe, K. B., \& Avolio, B. J. (2013). A meta-analysis of transformational and transactional leadership correlates of effectiveness and satisfaction: An update and extension. In Transformational and Charismatic Leadership: The Road Ahead 10th Anniversary Edition (pp. 39-70). Emerald Group Publishing Limited. https://doi.org/10.1108/S1479-357120130000005008.

8. Echevarria, I. M., Patterson, B. J., \& Krouse, A. (2017). Predictors of transformational leadership of nurse managers. Journal of nursing management, 25(3), 167-175. https://doi.org/10.1111/jonm.12452.

9. Ferris, G. R., Russ, G. S., Albanese, R., and Marlocchio, J. J. (1990). Personnel/human resource management, unionization, and strategydeterminates of organizational performance. Human Resource Plan-ning, 133. Available at:

https://web.a.ebscohost.com/abstract?direct=true \&profile=ehost\&scope=site \&authtype=crawler\&jrnl=01 998986\&asa=Y\&AN=7704711\&h=YlW4nOUIKxxBZYBjZv1r\%2bwz5PzFt7x7WqpgNgtmoZQhdtLjg0 2tlggv2vZsPTMb1pi91qrjeDcMh\%2fVNTk3gGig\%3d\%3d\&crl=c\&resultNs=AdminWebAuth\&resultLo cal=ErrCrlNotAuth\&crlhashurl=login.aspx \%3fdirect\%3dtrue\%26profile\%3dehost\%26scope $\% 3 \mathrm{dsite} \% 26$ authtype\%3dcrawler\%26jrnl\%3d01998986\%26asa\%3dY\%26AN\%3d7704711.

10.Hogeforster, J. (2001). Struktureller Wandel im Handwerk und zukünftige Leitbilder. In Handwerkskammer Hamburg (Ed.) [Structural Change in the field of crafts and future visions]. Zukunftsfähige Konzepte für das Handwerk zur Bewältigung des demographischen Wandels [Sustainable concepts for the craft trade sector to cope with demographic change]. Stuttgart: Frauenhofer IRB Verlag. https://www.ssoar.info/ssoar/bitstream/handle/document/23655/ssoar-2001-

zukunftsfahige_konzepte_fur_das_handwerk.pdf?sequence=1\&isAllowed=y\&lnkname=ssoar-2001zukunftsfahige_konzepte_fur_das_handwerk.pdf.

11.Holland, J. L. (1997). Making vocational choices: A theory of vocational personalities and work environments. Psychological Assessment Resources. https://lib.ugent.be/en/catalog/rug01:000421467.

12.Jiang, J. (2018, August). Transformational Leadership and Followers' Objective Performance: The Mediating Role of Leader-Member Exchange. In 2018 Engaged Management Scholarship Conference: Philadelphia, PA. https://doi.org/10.2139/ssrn.3240231.

13.Klaffke, M. (2014). Millennials und Generation Z - Charakteristika der nachrückenden ArbeitnehmerGenerationen. In Generationen-Management (pp. 57-82). Wiesbaden: Springer. 
https://doi.org/10.1007/978-3-658-02325-6_3.

14.Klaffke, M. \& Becker, K. A. (2012). Personalmanagement: Wie man im Krankenhaus den Ansprüchen der „Millenials“ gerecht werden kann [HR management: How hospitals can meet millenials' demands]. Deutsches Ärzteblatt - ̈̈rztliche Mitteilungen-Ausgabe A, 109(20), 1020. Available at: https://www.aerzteblatt.de/pdf.asp?id=126174.

15.Lowy, A., \& Hood, P. (2011). The power of the $2 \times 2$ matrix: Using $2 \times 2$ thinking to solve business problems and make better decisions. John Wiley \& Sons. Available at: https://epdf.pub/the-power-of-the2-x-2-matrix-using-2x2-thinking-to-solve-business-problems-and-.html.

16. Marin, D., \& Verdier, T. (2012). Globalization and the Empowerment of Talent. Journal of International Economics, 86(2), 209-223, Elsevier https://doi.org/10.1016/j.jinteco.2011.10.005.

17.Mayring, P. (1988). Qualitative Inhaltsanalyse: Grundlagen und Techniken [Qualitative content analyses - basics and techniques]. Weinheim: Deutscher Studien Verlag.

https://www.psychopen.eu/fileadmin/user_upload/books/mayring/ssoar-2014-mayring-

Qualitative_content_analysis_theoretical_foundation.pdf.

18.Neubauer, A. (2018). Mach, was du kannst: Warum wir unseren Begabungen folgen sollten-und nicht nur unseren Interessen. Mit Selbsttests [Do, what you can do: Why we should follow our talents and not only our interests]. DVA. https://www.randomhouse.de/Buch/Mach-was-du-kannst/Aljoscha-Neubauer/DVASachbuch/e519186.rhd.

19.Noe, R. A., Hollenbeck, J. R., Gerhart, B., \& Wright, P. M. (2017). Human resource management: Gaining a competitive advantage. New York, NY: McGraw-Hill Education. https://issuu.com/zoqqa75/docs/download-human-resource-management-.

20.Rauch, A., \& Frese, M. (2007). Let's put the person back into entrepreneurship research: A meta-analysis on the relationship between business owners' personality traits, business creation, and success. European Journal of work and organizational psychology, 16(4), 353-385. https://doi.org/10.1080/13594320701595438.

21.Rohwetter, M. (2013). Nutzen statt besitzen [Use instead of own]. Die Zeit, 11(2013), 27. Available at: https://www.zeit.de/2013/11/Cebit-Shareconomy-Wirtschaft-des-Teilens.

22.Sekaran, U., \& Bougie, R. (2016). Research methods for business: A skill building approach. John Wiley \& Sons. Available at: https://www.academia.edu/36294585/Research-Methods-For-Business-A-SkillBuilding-Approach-7th_edition.pdf.

23.Simons, T. L. (1999). Behavioral integrity as a critical ingredient for transformational leadership. Journal of Organizational Change Management, 12(2), 89-104. https://doi.org/10.1108/09534819910263640.

24.Tarnai, C., \& Hartmann, F. G. (2015). Berufliche Interessen. Beiträge zur Theorie von JL Holland [Professional interests. Contributions to the theory of JL Holland]. Münster, Germany: Waxmann. https://www.waxmann.com/waxmann-

buecher/?tx_p2waxmann_pi2\%5bbuchnr\%5d=3148\&tx_p2waxmann_pi2\%5baction\%5d=show.

25.Thoma, C. (2011). Erfolgreiches Retention Management von Millennials [Successfull retention management for millennials]. In M. Klaffke (Hrsg.), Personalmanagement von Millennials - Konzepte, Instrumente und Best Practice Ansätze (S. 163-180) [HR management for millenials - concepts, instruments and best practice cases]. Wiesbaden: Gabler. https://doi.org/10.1007/978-3-8349-6964-4_9.

26. Van Iddekinge, C. H., Roth, P. L., Putka, D. J., \& Lanivich, S. E. (2011). Are you interested? A metaanalysis of relations between vocational interests and employee performance and turnover. Journal of Applied Psychology, 96(6), 1167. https://doi.org/10.1037/a0024343. 